\title{
Antibody to Mycoplasma hominis in patients with respiratory disease
}

\author{
A. E. ELDRIDGE, D. M. JONES, AND BARBARA M. TOBIN
}

From the Central Serology Laboratory and Pathology Laboratory, Withington Hospital, Manchester

SYNOPSIS An attempt was made to evaluate the role of Mycoplasma hominis in respirator infection in adults. Sera collected from patients admitted to hospital with respiratory infection were examined for antibody to $M$. hominis. The incidence of antibody was no higher than that found previously in patients without respiratory disease.

A number of different species of mycoplasmas can be isolated from the upper respiratory tract of man but little evidence has been produced that they behave as pathogens. The exception is $\mathrm{Myco}$ plasma pneumoniae which is well recognized as a respiratory pathogen and is rarely isolated from the oropharynx of healthy individuals. $M$. hominis is a frequent commensal in the genital tract but can also be isolated from the oropharynx in a small percentage of people. A strain of this organism, M. hominis DC 63, was used in volunteer studies (Mufson, Ludwig, Purcell, Cate, Taylor-Robinson, and Chanock, 1965) and produced pharyngitis under experimental conditions. These studies raised the question whether $M$. hominis was ever a natural respiratory pathogen.

We report here the results of examining for antibodies to $M$. hominis a collection of acute and convalescent specimens of serum from patients admitted to hospital with acute respiratory disease. In these patients the most frequent diagnosis was pneumonia, with exacerbation of chronic bronchitis as the next most frequent condition. The antigenic heterogenicity of $M$. hominis strains has been demonstrated (Nicol and Edward, 1953; Purcell, Wong, Chanock, TaylorRobinson, Canchola, and Valdesuso, 1967) and for this reason more than one strain was used in our investigation. The incidence of antibodies to Received for publication 26 March 1970.
$M$. hominis in this group of patients with reso piratory disease is compared with that found pre 3 viously in others without this condition (Jones and Sequeira, 1966).

\section{Materials and Methods}

Three hundred and fifty-two specimens of serum that had been collected from 335 patients admitte to the Brompton Hospital, London, during the years 1966, 1967, and 1968, were kindly made available to us for testing by Dr B. E. Andrews and Dr J. Inglis. Three hundred and fifty-two sera were tested by the metabolic inhibition testu One hundred and eighty-one sera were tested by the complement-fixation test as the remain der of the specimens were found to be antie complementary. The techniques used have beemp described previously (Jones and Sequeira, 1966) In addition sera that gave positive results in the screening metabolic inhibition test at a dilution of $1 / 5$ were tested for the presence of antibiotif using glucose broth containing indicator and the Oxford staphylococcus as the test organism. These tests and the titrations of the metabolic inhibition antibody were performed in microtitre plates to conserve serum.

Complement-fixing antigens were prepared. 
with $M$. hominis DC 63, a strain kindly provided by Dr D. Taylor-Robinson, Salisbury, and with $M$. hominis M 130, a strain isolated by Dr B. E. Andrews, Colindale, from the respiratory tract of an adult. Also complement-fixing antigen prepared with $M$. hominis PG 21 was obtained from Baltimore Biological Laboratory. These three

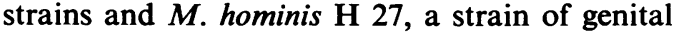
origin, were used for the metabolic inhibition tests.

\section{Results}

The age and sex of 198 patients and the sex of a further 105 patients were known. The sera were classified into those collected within 14 days of the onset of symptoms ( 98 acute specimens) and those collected later in the illness (194 convalescent specimens). Sixty sera were unclassifiable as the date of onset of disease was not known, but as most of the patients had been ill for some time before admission to hospital, it is likely that these sera were mainly in the convalescent category.

All the sera were examined by the metabolic inhibition technique to the four strains of $M$. hominis and 181 sera were examined by the complement-fixation technique using the three antigens. Twenty-four sera (12 acute, 5 convalescent, 7 unclassified) were found to inhibit the Oxford staphylococcus as well as the strains of $M$. hominis; this inhibition was presumed to be due to antibiotic in the serum and these results were deleted from the analysis of the metabolic inhibition test results.

\begin{tabular}{|c|c|c|c|c|c|}
\hline \multirow{2}{*}{$\begin{array}{l}\text { Strains of } \\
\text { M. } \\
\text { hominis }\end{array}$} & \multirow{2}{*}{$\begin{array}{l}\text { No. of } \\
\text { Sera } \\
\text { Positive }\end{array}$} & \multicolumn{4}{|c|}{ No. of Sera with Titres of } \\
\hline & & $\begin{array}{l}>1 / 5 \text { Rising } \\
\text { to } 1 / 5\end{array}$ & $\begin{array}{l}>1 / 5 \text { Rising } \\
\text { to } 1 / 10\end{array}$ & $1 / 5 \quad 1 / 10$ & $1 / 20$ \\
\hline $\begin{array}{l}\text { H27 } \\
\text { PG21 } \\
\text { DC63 } \\
\text { M130 }\end{array}$ & $\begin{array}{l}5(1.5 \%) \\
6(1.8 \%) \\
5(1.5 \%) \\
4(1.2 \%)\end{array}$ & $\begin{array}{l}2^{\mathrm{ab}} \\
1^{\mathrm{b}} \\
1^{\mathrm{b}} \\
2^{\mathrm{ab}}\end{array}$ & $\begin{array}{l}0 \\
1^{\mathrm{c}} \\
0 \\
0\end{array}$ & $\begin{array}{ll}3^{\text {def }} & 0 \\
3^{\text {dfg }} & 1^{\mathrm{h}} \\
3^{\text {dfg }} & 0 \\
1^{f} & 1^{\text {d }}\end{array}$ & $\begin{array}{l}0 \\
0 \\
1^{\mathbf{h}} \\
0\end{array}$ \\
\hline
\end{tabular}

Table I Results of testing 328 sera by the metabolic inhibition test ${ }^{1}$

${ }^{1}$ Individual patients are denoted by letters $a-h$.

\begin{tabular}{lllll}
\hline No. of Sera & \multicolumn{4}{l}{ No. of Sera Reacting with } \\
\cline { 2 - 5 } & $H 27$ & $D C 63$ & $P G 21$ & $M 130$ \\
\hline Acute 85 & 0 & 0 & 0 & 0 \\
Convalescent 189 & 3 & 2 & 2 & 3 \\
& $(1.6 \%)$ & $(1.1 \%)$ & $(1.1 \%)$ & $(1.6 \%)$ \\
\hline
\end{tabular}

Table II Incidence of metabolic inhibition antibody in acute and convalescent sera
ISOLATION OF M. HOMINIS

During the study a strain of $M$. hominis was isolated from the respiratory tract of one of the 음 patients. There was no detectable complementfixing antibody to $M$. hominis $\mathrm{PG} 21$ in paired sera from this patient, and no detectable metabolic inhibition antibody using the homologous strain in the test.

METABOLIC-INHIBITION TEST RESULTS The number of sera that reacted with each strain of $M$. hominis is shown in Table I. The total of 20 positive results was derived from the sera of eight patients $(2.4 \%$ of the 335 patients in the study) and the pattern of reaction with different strains is shown. In only three patients were the antibody titres in excess of $1 / 5$. In only one patient (c) was $\dot{0}$ there an unequivocal rise in metabolic inhibition antibody titre. The difference in incidence of $\stackrel{A}{A}$ antibody classified as acute and convalescent is 은 shown in Table II and is not regarded as significant.

COMPLEMENT-FIXATION TEST RESULTS The sera from 172 patients were tested by the $\Phi$ complement-fixation technique. The number of $\vec{\varphi}$ sera with titres of $1 / 5$ or greater with each antigen is shown in Table III. No titres in excess of $1 / 10$. were detected. The number of sera that reacted with one or more of the antigens was $41(24 \%)$. Twenty-three out of 109 male patients were posi-o tive $(21 \%)$ and 18 out of 63 female patients were $\frac{\%}{8}$ positive $(29 \%)$. The incidence of antibody detected $\triangle$ in acute and convalescent sera was not signifi- $\overrightarrow{\vec{O}}$ cantly different (Table IV).

More sera reacted with DC 63 and M 130 than

\begin{tabular}{|c|c|c|c|c|c|}
\hline \multirow[t]{2}{*}{ Antigen } & \multirow{2}{*}{$\begin{array}{l}\text { No. of Sera } \\
\text { Positive }\end{array}$} & \multicolumn{4}{|c|}{ No. of Sera with Titres of } \\
\hline & & $\begin{array}{l}>1 / 5 \text { Rising } \\
\text { to } 1 / 5\end{array}$ & $\begin{array}{l}>1 / 5 \text { Rising } \\
\text { to } 1 / 10\end{array}$ & $1 / 5$ & $1 / 10$ \\
\hline $\begin{array}{l}\text { PG } 21 \\
\text { DC } 63 \\
\text { M } 130\end{array}$ & $\begin{array}{l}23(13 \%) \\
29(16 \%) \\
30(16 \%)\end{array}$ & $\begin{array}{l}0 \\
2^{1 j} \\
2^{1 j}\end{array}$ & $\begin{array}{l}11 \\
0 \\
0\end{array}$ & $\begin{array}{l}20 \\
23 \\
21\end{array}$ & $\begin{array}{l}2 \\
4 \\
7\end{array}$ \\
\hline
\end{tabular}

Table III Results of testing 181 sera by the comple- N ment-fixation test ${ }^{1}$

${ }^{1}$ Individual patients are denoted by letters $\mathrm{i}-\mathrm{j}$

\begin{tabular}{lllll}
\hline No. of Sera & \multicolumn{3}{l}{ No. of Sera } & Reacting with \\
\cline { 2 - 5 } & $P G 21$ & DC 63 & $M 130$ \\
\hline Acute 54 & $7(13 \%)$ & $10(18 \%)$ & $10(18 \%)$ \\
Convalescent 99 & $13(13 \%)$ & $14(14 \%)$ & $14(14 \%)$ \\
\hline Table IV The incidence of complement-fixation \\
antibody in acute and convalescent sera.
\end{tabular}




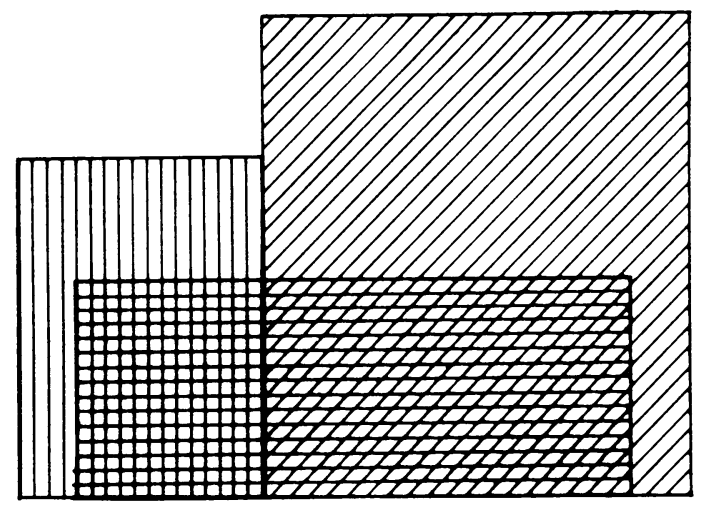

Fig. Representation of the proportions of sera reacting with various $\mathrm{M}$. hominis $C F$ antigens.

with PG $21 ; 10$ sera reacted with all three antigens, 19 sera with DC 63 and M 130 only, 11 sera with PG 21 only, and one serum reacted with M 130 only. No reactions were recorded with DC 63 alone or with the combinations of PG 21 and DC 63 or PG 21 and M 130. These relationships are shown in the figure diagrammatically.

\section{Discussion}

The frequency with which $M$. hominis has been isolated from the respiratory tract has varied with different workers but has always been of a low order (Organick and Worman, 1966; Kundsin and Praznik, 1967). Klein, Buckland, and Finland (1969) isolated $M$. hominis from the throat of approximately $3 \%$ of neonates and it has been our experience also that this organism may be isolated from a small proportion of newborn babies without any suggestion that it causes symptoms. It may be that those individuals who acquire this organism in the throat in early life continue to carry it in adulthood as a commensal.

Glezen, Thornburg, Chin, and Wenner (1967), studying children during two winter periods, and Stewart and Chowdray (1968), studying a large number of adults and children, failed to isolate $M$. hominis from patients with respiratory disease and from controls without this disease. However, during a prolonged microbiological study in the United States, Mufson, Chang, Gill, Wood, Romansky, and Chanock (1967) isolated mycoplasmas other than M. pneumoniae from $53 \%$ of 427 patients with pneumonia and from $47 \%$ of 1,134 of patients without respiratory disease. These workers identified a random half of the mycoplasmas they isolated; $6.9 \%$ of those from the pneumonia group were $M$. hominis. whereas $3.4 \%$ of them from the controls were this organism. They demonstrated antibody tọ M. hominis in $3.8 \%$ of the pneumonia group and $0.3 \%$ of controls and on this evidence suggeste that $M$. hominis might be associated with pneuc monia. It was during this study that $M$. homini DC 63 was isolated from a patient with pneumonif who subsequently developed homologous fluo@ rescent-stainable and complement-fixing anti⿱ body. Complement-fixing antibody to $M$. hominis DC 63 was not, however, demonstrated in any of the 17 other patients from whom $M$. hominis wa $\vec{\delta}$ isolated. In our one respiratory patient frons whom M. hominis was isolated, no immunoo logical response to this organism was demoni strable.

Mufson et al (1965), by giving a large intranasaigs dose of $M$. hominis, produced pharyngitis with \& concommitant antibody response, measurable bo indirect haemagglutination, but significantly not by complement fixation.

The form of the immunological responses it puerperal infections associated with M. homini has been recorded (Stokes, 1955; Tully an $\$$ Smith, 1968; Jones and Tobin, 1969), and in one of the cases studied by Stokes a mycoplasma was isolated from an empyema following lobectomy, By inference, if $M$. hominis played a part, ever only a subsidiary role, in respiratory infections then an increased incidence of antibody would b expected in the patients we have studied compare with others without respiratory disease.

The incidence of metabolic inhibition antibod $\overrightarrow{\vec{B}}$ in these patients with respiratory disorders $(2.4 \%$ is of the same order, although lower than tha detected in over 600 hospital patients in the earlier study (females $4.5 \%$, males $3.2 \%$ ). This lower result may have been affected by the deletion of $7 \%$ of the apparently positive metabolie inhibition sera from the analysis as they containe antibiotic.

The incidence of complement-fixation antibod $\$$ detected by a single antigen in the present stud? ranged from 13 to $16 \%$ but the three antigen together detected antibody in $24 \%$ of the sera. I the earlier study the incidence of complementer fixing antibody with one antigen was $16 \%$ in 2,265 females and $10 \%$ in 560 males. This has demonstrated the value of using more than one antigen in a serological survey for antibody to M. hominis.

Allowing for differences in the age and se必 distribution of the patients in this study, there was no significant difference in the incidence of ant $\overline{5}$

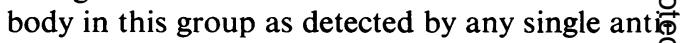
gen compared with that found in patients in the earlier study. No significant differences between sera classified as acute and convalescent were demonstrated. We conclude that in the absenceg of any detectable increase in incidence of ant body, using techniques known to be capable detecting such responses, it is unlikely that $M P$ 
hominis had any part in the illness of the group of patients studied.

This work was supported by a research grant from the Manchester Regional Hospital Board.

\section{References}

Glezen, W. P., Thornburg, G., Chin, T. D. Y., and Wenner, H. A. (1967). Significance of mycoplasma infections in children with respiratory disease. Pediatrics, 39, 516-525.

Jones, D. M., and Sequeira, P. J. L. (1966). The distribution of complement-fixing antibody and growth-inhibiting antibody to Mycoplasma hominis. J. Hyg. (Lond.), 64, 441-449.

Jones, D. M., and Tobin, B. M. (1969). Isolation of mycoplasma and other organisms from the placenta after Caesarean section. J. med. Microbiol., 2, 347-352.

Klein, J. O., Buckland, D., and Finland, M. (1969). Colonization of newborn infants by mycoplasmas. New. Engl. med. J., 280, 1025-1030.
Kundsin, R. B., and Praznik, J. (1967). Pharyngeal carriage of mycoplasma species in healthy young adults. Amer. J. Epidem., 86, 579-583.

Mufson, M. A., Ludwig, W. M., Purcell, R. H., Cate, T. R., Taylor-Robinson, D., and Chanock R. M. (1965). Exuda- 을 tive pharyngitis following experimental Mycoplasma $\Rightarrow$ hominis: type 1 infection. J. Amer. med. Ass., 192, 1146- जे 1152.

Mufson, M. A., Chang, V., Gill, V., Wood, S. C., Romansky, M. J., and Chanock, R. M. (1967). The role of viruses, mycoplasmas and bacteria in acute pneumonia in civilian adults. Amer. J. Epidem., 86, 526-544.

Nicol, C. S., and Edward, D. G. ff. (1953). Role of organisms of the pleuropneumonia group in human genital infections.
Brit. J. vener. Dis., 29, 141-150.

Organick, A. B., and Worman, L. W. (1967). Isolation and identification of mycoplasma from the lower respiratory tract in bronchoscopy patients. Amer. Rev. resp. Dis., 95, 618-622.

Purcell, R. H., Wong, D., Chanock, R. M., Taylor-Robinson, D., Canchola, J., and Valdesuso, J. (1967). Significance of antibody to mycoplasma as measured by metabolic-inhibition techniques. Ann. N.Y. Acad. Sci., 143, 664-675.

Stewart, S. M., and Chowdray, J. E. (1968). Isolation of myco- W plasmas from the human respiratory tract. J. Path. Bact., $95,580-586$

Stokes, E. J. (1955). Human infection with pleuropneumonia-like organisms. Lancet, 1, 276-279.

Tully, J. G., and Smith, L. G. (1968). Postpartum septicemia with Mycoplasma hominis. J. Amer. med. Ass., 204, 827-828. 